\title{
Total Phenolic Content and Antioxidant Activity of Red and Yellow Quinoa (Chenopodium quinoa Willd.) Seeds as Affected by Baking and Cooking Conditions
}

\author{
Yael Brend, Liel Galili, Hana Badani, Ran Hovav, Shmuel Galili* \\ Agronomy and Natural Resources Department, Agricultural Research Organization, The Volcani Center, Bet Dagan, Israel. \\ Email: *galilis@agri.gov.il
}

Received January $25^{\text {th }}, 2012$; revised July $13^{\text {th }}, 2012$; accepted July $20^{\text {th }}, 2012$

\begin{abstract}
Seeds with colored testa (seed coat) contain high concentrations of polyphenolic compounds that exhibit high levels of antioxidant activity. Common processing procedures, such as cooking and baking, decrease the levels of these bioactive compounds and consequently, overall antioxidant activity. Here, the effects of baking and cooking processes were examined on total phenolic content (TPC), total flavonoid content (TFC) and ferric-reducing ability of plasma antioxidant activity (FRAP AA) of red and yellow quinoa seeds. Our results indicate that red quinoa seed contains significantly higher levels of TPC, TFC and FRAP AA than yellow quinoa seeds. In addition, cooked and baked quinoa seeds retain most of their TPC, TFC and FRAP AA in the final product. Thus, red quinoa seeds processed by these two methods might be considered a functional food, in addition to its traditional role of providing dietary proteins. Due to their high antioxidant activity, red quinoa seeds might also contribute significantly to the management and/or prevention of degenerative diseases associated with free radical damage.
\end{abstract}

Keywords: Colored Quinoa Seeds; Processing; Total Phenolics; Total Flavonoids; FRAP

\section{Introduction}

Quinoa (Chenopodium quinoa Willd.) is one of the most important Andean grain crops, classified as a pseudocereal used principally in the same manner as wheat and rice. This crop has been cultivated in the Andean highlands since $3000 \mathrm{BC}$ [1]. Quinoa seeds contain carbohydrates $(77.6 \%)$, protein $(12.9 \%)$, a balanced amino acid spectrum with high lysine and methionine contents, and lipids $(6.5 \%)$, and they are rich in dietary fibers and minerals [2-6]. Due to its high nutritional quality, interest in quinoa is growing in other parts of the world.

Polyphenols are bioactive secondary plant metabolites that are widely present in commonly consumed foods of plant origin. The three main types of polyphenols are flavonoids, phenolic acids and tannins, which act as powerful antioxidants in vitro. These compounds are considered to have many potential beneficial health effects, including antioxidant, apoptotic, antiaging, anticarcinogenic and anti-inflammatory activities, cardiovascular protection and improvement of endothelial function. Polyphenols also inhibit angiogenesis and cell proliferation (reviewed by Han et al. [7]). Recent studies have

"Corresponding author. identified quinoa seeds as a good source of bioactivepolyphenols which might change antioxidant status in the organism and prevent oxidative stress [8-12]. Quinoa seeds were shown to act as a moderate protective agent against potential fructose-induced changes in rats by reducing lipid peroxidation and by enhancing the antioxidant capacity of the blood (plasma), heart, kidney, testis, lung and pancreas [13]. However, like other grain seeds, quinoa must be baked or cooked prior to consumption. These processing procedures improve the flavor and palatability of the food product, but they might also decrease the levels of bioactive compounds and antioxidant activity of these foods, as has been shown for other grain seeds, including quinoa [14-17]. To explore their potential use as functional foods, we determined the effects of baking and cooking conditions on the levels of bioactive compounds (polyphenols and flavonoids) and antioxidant activity in vitro, in red and yellow quinoa seeds.

\section{Materials and Methods}

\subsection{Plant Material}

Two types of quinoa seed, red and yellow, were used in this study. Both types were purchased from a local 
health-food store.

\subsection{Cooking and Baking}

Quinoa seeds $(150 \mathrm{~g})$ were immersed in $270 \mathrm{~mL}$ tap water and brought to a boil in a $2 \mathrm{~L}$ pot. Cooking was stopped after 12 min of continued boiling when all of the water had been absorbed by the seeds. For baking, quinoa flour was obtained by grinding the seeds to a fine powder (60 mesh). Quinoa bread was made from dough containing $200 \mathrm{~g}$ quinoa flour and $200 \mathrm{ml}$ tap water. The dough was divided into rolls, $30 \mathrm{~g}$ each, and baked at $150^{\circ} \mathrm{C}$ for $25 \mathrm{~min}$. Cooked and baked quinoa products were freeze-dried, ground to a fine powder $(60 \mathrm{mesh})$ in liquid nitrogen with a mortar and pestle and kept at $-20^{\circ} \mathrm{C}$ until use.

\subsection{Extraction of Total Polyphenols}

Quinoa seeds were ground to a fine powder (60 mesh) in a Retsch MM301 grinder. A $100 \mathrm{mg}$ portion of the powder (for solvents 1 - 5) and $50 \mathrm{mg}$ powder (for solvent 6) were extracted in a $2 \mathrm{~mL}$ microfuge tube with $1 \mathrm{~mL}$ of the following solvents (Bio-Lab, Israel): 1) acetone/water $(50: 50, \mathrm{v} / \mathrm{v}) ; 2)$ acetone/water $(80: 20, \mathrm{v} / \mathrm{v}) ; 3)$ acetone/ water/acetic acid $(70: 29.5: 0.5, \mathrm{v} / \mathrm{v}) ; 4)$ methanol/water/ acetic acid $(65: 29: 6, \mathrm{v} / \mathrm{v}) ; 5)$ methanol/water $(70: 30, \mathrm{v} / \mathrm{v})$, as previously described [18]; and 6) methanol/hydrochloric acid/water $(8: 1: 1, \mathrm{v} / \mathrm{v})$ [9]. The mixture was shaken at $300 \mathrm{rpm}$ at ambient temperature for $2 \mathrm{~h}$ in the dark followed by centrifugation at $10,000 \mathrm{~g}$ for $5 \mathrm{~min}$ at ambient temperature. Supernatant was transferred to a new tube and the pellet was re-extracted in an additional $1 \mathrm{~mL}$ of the same solvents $(1-5)$ and with $2 \mathrm{~mL}$ of $70 \%$ acetone for $2 \mathrm{~h}$ instead of solvent 6 . The supernatants were combined with the previous ones and stored in the dark in a freezer at a temperature of $-20^{\circ} \mathrm{C}$ until use for determination of total polyphenol content (TPC), total flavonoid content (TFC), and ferric-reducing ability of plasma (FRAP) antioxidant activity (AA) [9].

\subsection{Determination of TPC, TFC and FRAP AA}

TPC, in milligram catechin equivalents (CE) per gram, was determined on a dry matter basis using the FolinCiocalteu assay $[19,20]$ and TFC (mg CE/g) was determined using a colorimetric method [21] in $50 \mu \mathrm{L}$ of extracted sample, as described previously by Segev et al. [18]. The FRAP AA method was used to evaluate the antioxidant activity, in millimole trolox equivalents (TE) per 100 gram of quinoa extract, by measuring the ferricreducing ability of plasma at low $\mathrm{pH}$ levels [22] as previously described [18].

\subsection{Statistical Analysis}

Analyses were performed in triplicate. The data were analyzed by ANOVA using JMP (Version 5.0). Tukey HSD multiple-range tests were carried out to detect significant differences between lines and between treatments. A Pearson correlation test was conducted to determine the correlations among variables. Level of significance was defined as $P \leq 0.05$.

\section{Results and Discussion}

\subsection{Influence of Extraction Solvents on TPC, TFC and FRAP AA}

Different solvents were found to have different extraction efficiencies for TPC and TFC, which exhibited high levels of antioxidant activity [18,23]. We first determined the effects of the various extraction solvents on TPC, TFC and FRAP AA extracted from red and yellow quinoa seeds (Table 1). Small but significant differences in TPC, TFC and FRAP AA were observed between the different solvents and within seed colors (Table 1(a)). Solvents 1 (50\% acetone) and 6 (acidic methanol $+70 \%$ acetone) extracted significantly more TPC than solvent 4 ( $70 \%$ methanol); solvent 6 extracted significantly more TFC than all other solvents except solvent $2(80 \%$ acetone), and extract of solvent 2 exhibited significantly more FRAP AA than that with solvent 4 . We selected solvent 6 as the best overall extraction solvent for further extractions.

Table 1(b) shows that red quinoa seeds had significantly higher levels of TPC, TFC and FRAP AA than yellow quinoa seeds: the dry red quinoa seeds contained about $50 \%, 90 \%$ and $300 \%$ more TPC, TFC and FRAP AA, respectively, than the yellow seeds. Similar observations of colored seeds having more TPC, TFC and antioxidant activity than beige-color seeds have been made in colored chickpeas $[16,18]$, soybean and common bean [24], cowpea [25], and peanuts [26,27]. The levels of TPC observed here were higher than those reported by Pasko et al. [10] and Miranda et al. [28], but lower than those reported by Nsimba et al. [29], and the levels of TFC were similar to those obtained by Repo-CarrascoValencia et al. [11]. These differences might result from the different standards used.

Table 2 shows significant linear correlations between TPC and TFC $(P<0.001)$, TPC and FRAP AA $(P<$ $0.001)$, and TFC and FRAP AA $(P<0.001)$. These correlations were higher than those obtained by Miranda et al. [28] and Nsimba et al. [29], but somewhat lower than those previously observed for quinoa [30] and other seed legumes $[18,24]$. Our results support the suggestion that in some quinoa seeds, antioxidant activity might also 
Table 1. Effect of extraction solvent (a) and seed color (b) on total phenolic compounds (TPC), total flavonoid compounds (TFC) and FRAP antioxidant activity (AA) of quinoa seeds.

(a)

\begin{tabular}{cccc}
\hline Solvent No. & TPC & TFC & FRAP AA \\
\hline 1 & $1.45 \pm 0.1 \mathrm{a}$ & $0.7 \pm 0.1 \mathrm{bc}$ & $3.5 \pm 0.3 \mathrm{ab}$ \\
2 & $1.35 \pm 0.1 \mathrm{ab}$ & $0.9 \pm 0.1 \mathrm{ab}$ & $3.6 \pm 0.3 \mathrm{a}$ \\
3 & $1.38 \pm 0.1 \mathrm{ab}$ & $0.8 \pm 0.1 \mathrm{bc}$ & $3.5 \pm 0.3 \mathrm{ab}$ \\
4 & $1.05 \pm 0.1 \mathrm{~b}$ & $0.6 \pm 0.1 \mathrm{c}$ & $2.4 \pm 0.3 \mathrm{~b}$ \\
5 & $1.13 \pm 0.1 \mathrm{ab}$ & $0.5 \pm 0.1 \mathrm{c}$ & $2.7 \pm 0.3 \mathrm{ab}$ \\
6 & $1.44 \pm 0.1 \mathrm{a}$ & $1.1 \pm 0.1 \mathrm{a}$ & $3.0 \pm 0.3 \mathrm{ab}$ \\
\hline
\end{tabular}

(b)

\begin{tabular}{cccc}
\hline Color & TPC & TFC & FRAP \\
\hline Red & $2.1 \pm 0.1 \mathrm{a}$ & $1.9 \pm 0.1 \mathrm{a}$ & $5.1 \pm 0.2 \mathrm{a}$ \\
Yellow & $1.4 \pm 0.1 \mathrm{~b}$ & $0.9 \pm 0.1 \mathrm{~b}$ & $1.7 \pm 0.1 \mathrm{~b}$ \\
\hline
\end{tabular}

Table 2. Correlations between TPC, TFC and FRAP AA.

\begin{tabular}{ccc}
\hline & TFC & FRAP AA \\
\hline TPC & 0.85 & 0.78 \\
FRAP AA & 0.68 & \\
\hline
\end{tabular}

Note: All correlations were significant at the 0.001 level (2-tailed).

derive from proteins and other non-phenolic compounds $[29,31,32]$.

\subsection{Effects of Cooking and Baking on TPC, TFC and FRAP AA}

The effects of cooking on TPC, TFC and FRAP AA are shown in Figure 1. In all cases except TPC after cooking, red quinoa seeds had significantly higher levels of TPC, TFC and FRAP AA than yellow quinoa seeds. In most cases, cooking did not cause any significant changes in these three parameters (Figure 1). The significant increase in FRAP AA in yellow quinoa seeds (Figure 1(c)) might have derived from a small, non-significant increase in TPC (Figure 1(a)). Thus, cooked quinoa retained high levels of TPC, TFC and FRAP AA and can be considered a functional food. Similar results were obtained by Brady et al. [33] in which steaming for up to $60 \mathrm{~min}$ also did not affect the composition of quinoa flour. Our results are in contrast to those obtained for seed legumes, in which cooking legume seeds results in a significant reduction in these three parameters $[16,17,34]$,

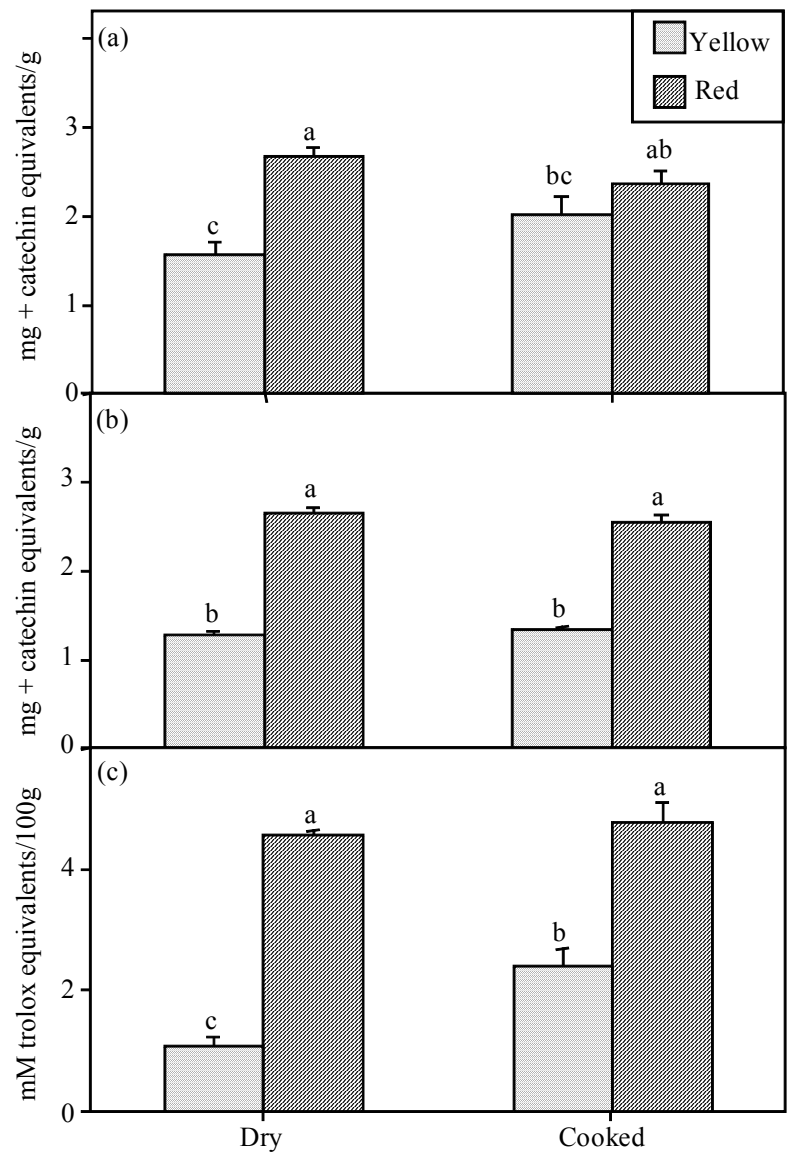

Figure 1. Effect of cooking on total phenolic content (a), total flavonoid content (b) and antioxidant activity (c) in red and yellow quinoa seeds. Bar represents mean \pm standard error from at least three replicates. Values marked by the same letter above each column are not significantly different $(P<0.05)$.

because most of the TPC, TFC and FRAP AA leaked into the cooking water [16]. Thus, the conservation of TPC, TFC and FRAP AA in quinoa seeds after cooking might be due to the fact that quinoa seeds absorb all of the cooking water.

The effects of baking on TPC, TFC and FRAP AA are shown in Figure 2. Similar to that which was found with the cooking process, in all cases red quinoa seeds had significantly higher levels of TPC, TFC and FRAP AA than yellow quinoa seeds. Baking did not cause any significant changes in TPC, but TFC levels were significantly reduced. FRAP AA increased in red quinoa seeds and did not change in the yellow seeds. This increase in antioxidant activity might have been due to the Maillard reaction products produced during the thermal processing [35]. Similar observations have been made with baked rhubarb, in which both TPC and FRAP AA were at higher levels during the first 20 min of baking and then decreased to low levels [36], and in baked chocolate 


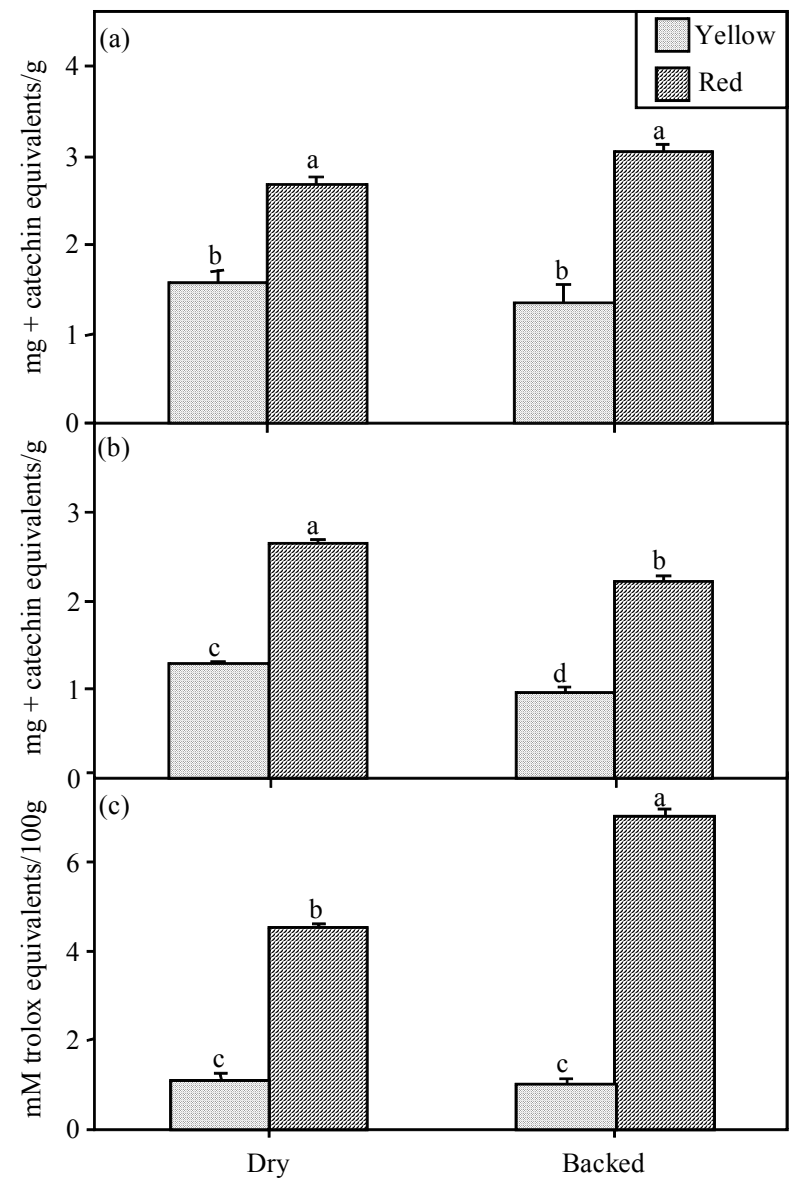

Figure 2. Effect of baking on total phenolic content (a), total flavonoid content (b) and antioxidant activity (c) in red and yellow quinoa seeds. Bar represents means \pm standard error from at least three replicates. Values marked by the same letter above each column are not significantly different $(P<$ 0.05).

cookies and chocolate cakes made with baking powder rather than baking soda $[37,38]$.

\section{Conclusion}

Our results indicate that cooked and baked quinoa seeds retain most of their TPC, TFC and FRAP AA in the final product. In addition, red quinoa seeds have significantly higher levels of TPC, TFC and FRAP AA than regular yellow seeds. Thus, red quinoa seeds subjected to these two processing methods might be considered a functional food, in addition to their traditional role of providing dietary proteins. Red quinoa seeds, due to their high antioxidant activity, might also markedly contribute to the management and/or prevention of degenerative diseases associated with free radical damage. Future research should be conducted to verify that colored quinoa seeds can be used for management and/or prevention of such degenerative diseases.

\section{REFERENCES}

[1] M. Tapia, "The Environment, Crops and Agricultural Systems in the Andes of Southern Peru," IICA, 1982.

[2] H. Ando, Y. Chen, H. Tang, M. Shimizu, K. Watanabe and T. Mitsunaga, "Food Components in Fractions of Quinoa Seed," Food Science Technology Reseach, Vol. 8, 2002, pp. 80-84. doi:10.3136/fstr.8.80

[3] Y. Konishi, S. Hirano, H. Tsuboi and M. Wada, "Distribution of Minerals in Quinoa (Chenopodium quinoa Willd.) Seeds," Bioscience, Biotechnology and Biochemistry, Vol. 68, No. 1, 2004, pp. 231-234. doi:10.1271/bbb.68.231

[4] M. Koziol, "Chemical Composition and Nutritional Evaluation of Quinoa (Chenopodium quinoa Willd.)," Journal of Food Composition Analysis, Vol. 5, No. 1, 1992, pp. 35-68. doi:10.1016/0889-1575(92)90006-6

[5] G. Ranhotra, J. Gelroth, B. Glaser, K. Lorenz and D. Johnson, "Composition and Protein Nutritional Quality of Quinoa," Cereal Chemistry, Vol. 70, 1993, pp. 303-305.

[6] R. Repo-Carrasco, C. Espinoza and S. E. Jacobsen, "Nutritional Value and Use of the Andean Crops Quinoa (Chenopodium quinoa) and Kaniwa (Chenopodium pallidicaule)," Food Reviews International, Vol. 19, No. 1-2, 2003, pp. 179-189. doi:10.1081/FRI-120018884

[7] X. Han, T. Shen and H. Lou, "Dietary Polyphenols and Their Biological Significance," International Journal of Molecular Science, Vol. 8, No. 9, 2007, pp. 950-988. doi: $10.3390 / 18090950$

[8] S. Gorinstein, O.-J. Medina Vargas, N.-O. Jaramillo, I. Arnao Salas, A.-L. Martinez Ayala, P. Arancibia-Avila, F. Toledo, E. Katrich and S. Trakhtenberg, "The Total Polyphenols and the Antioxidant Potentials of Some Selected Cereals and Pseudocereals," European Food Research and Technology, Vol. 225, No. 3, 2007, pp. 321328. doi:10.1007/s00217-006-0417-7

[9] P. Paśko, H. Bartoń, P. Zagrodzki, S. Gorinstein, M. Fołta and Z. Zachwieja, "Anthocyanins, Total Polyphenols and Antioxidant Activity in Amaranth and Quinoa Seeds and Sprouts during Their Growth," Food Chemistry, Vol. 115, No. 3, 2009, pp. 994-998. doi:10.1016/j.foodchem.2009.01.037

[10] P. Pasko, M. Sajewicz, S. Gorinstein and Z. Zachwieja, "Analysis of Selected Phenolic Acids and Flavonoids in Amaranthus cruentus and Chenopodium quinoa Seeds and Sprouts by HPLC," Acta Chromomatographica, Vol. 20, 2008, pp. 661-672. doi:10.1556/AChrom.20.2008.4.11

[11] R. Repo-Carrasco-Valencia, J. K. Hellström, J.-M. Pihlava and P. H. Mattila, "Flavonoids and Other Phenolic Compounds in Andean Indigenous Grains: Quinoa (Chenopodium quinoa), Kañiwa (Chenopodium pallidicaule) and Iwicha (Amaranthus caudatus)," Food Chemistry, Vol. 120, 2010, pp. 128-133. doi:10.1016/j.foodchem.2009.09.087

[12] E. Ryan, K. Galvin, T. O'Connor, A. Maguire and N. O'Brien, "Phytosterol, Squalene, Tocopherol Content and Fatty Acid Profile of Selected Seeds, Grains, and Leg- 
umes," Plant Foods for Human Nutrition, Vol. 62, No. 1, 2007, pp. 85-91. doi:10.1007/s11130-007-0046-8

[13] P. Pasko, H. Barton, P. Zagrodzki, A. Izewska, M. Krosniak, M. Gawlik and S. Gorinstein, "Effect of Diet Supplemented with Quinoa Seeds on Oxidative Status in Plasma and Selected Tissues of High Fructose-Fed Rats," Plant Foods for Human Nutrition, Vol. 65, No. 3, 2010, pp. 146-151. doi:10.1007/s11130-010-0164-6

[14] L. Alvarez-Jubete, H. Wijngaard, E. K. Arendt and E. Gallagher, "Polyphenol Composition and in Vitro Antioxidant Activity of Amaranth, Quinoa Buckwheat and Wheat as Affected by Sprouting and Baking," Food Chemistry, Vol. 119, No. 2, 2010, pp. 770-778. doi:10.1016/j.foodchem.2009.07.032

[15] I. Dini, G. C. Tenore and A. Dini, “Antioxidant Compound Contents and Antioxidant Activity before and after Cooking in Sweet and Bitter Chenopodium Quinoa Seeds," LWT: Food Science and Technology, Vol. 43, No. 3, 2010, pp. 447-451. doi:10.1016/j.lwt.2009.09.010

[16] A. Segev, H. Badani, L. Galili, R. Hovav, Y. Kapulnik, I. Shomer and S. Galili, "Total Phenolic Content and Antioxidant Activity of Chickpea (Cicer arietinum L.) as Affected by Soaking and Cooking Conditions," Journal of Food Nutritional Sciences, Vol. 2, 2011, pp. 724-730. doi:10.4236/fns.2011.27099

[17] B. Xu and S. K. C. Chang, "Effect of Soaking, Boiling, and Steaming on Total Phenolic Content and Antioxidant Activities of Cool Season Food Legumes," Food Chemistry, Vol. 110, No. 1, 2008, pp. 1-13. doi:10.1016/j.foodchem.2008.01.045

[18] A. Segev, H. Badani, Y. Kapulnik, I. Shomer, M. OrenShamir and S. Galili, "Determination of Polyphenols, Flavonoids, and Antioxidant Capacity in Colored Chickpea (Cicer arietinum L.)," Journal of Food Science, Vol. 75, No. 2, 2010, pp. S115-S119. doi:10.1111/j.1750-3841.2009.01477.x

[19] V. L. Singleton, R. Orthofer and R. M. Lamuela-Raventos, "Analysis of Total Phenols and Other Oxidation Substrates and Antioxidants by Means of Folin-Ciocalteu Reagent," Methods in Enzymology, Vol. 299, 1999, pp. 152-178. doi:10.1016/S0076-6879(99)99017-1

[20] V. L. Singleton and J. A. Rossi, "Colorimetry of Total Phenolics with Phosphomolybdic-Phosphotungstic Acid Reagents," American Journal of Enology and Viticulture, Vol. 16, No. 3, 1965, pp. 144-158.

[21] D. Heimler, P. Vignolini, M. G. Dini and A. Romani, "Rapid Tests to Assess the Antioxidant Activity of Phaseolus vulgaris L. Dry Beans," Journal of Agricultural and Food Chemistry, Vol. 53, No. 8, 2005, pp. 3053-3056. doi:10.1021/jf049001r

[22] I. F. F. Benzie and J. J. Strain, "The Ferric Reducing Ability of Plasma (FRAP) as a Measure of "Antioxidant Power': The FRAP Assay," Analytical Biochemistry, Vol. 239, No. 1, 1996, pp. 70-76. doi:10.1006/abio.1996.0292

[23] B. J. Xu and S. K. C. Chang, "A Comparative Study on Phenolic Profiles and Antioxidant Activities of Legumes as Affected by Extraction Solvents," Journal of Food Science, Vol. 72, No. 2, 2007, pp. S159-S166.

\section{doi:10.1111/j.1750-3841.2006.00260.x}

[24] B. J. Xu, S. H. Yuan and S. K. C. Chang, "Comparative Analyses of Phenolic Composition, Antioxidant Capacity, and Color of Cool Season Legumes and Other Selected Food Legumes," Journal of Food Science, Vol. 72, No. 7, 2007, pp. S167-S177. doi:10.1111/j.1750-3841.2006.00261.x

[25] D. P. Kachare, J. K. Chavan and S. S. Kadam, "Nutritional Quality of some Improved Cultivars of Cowpea," Plant Foods for Human Nutrition, Vol. 38, No. 2, 1988, pp. 155-162. doi:10.1007/BF01091720

[26] Y. Chukwumah, L. T. Walker and M. Verghese, "Peanut Skin Color: A Biomarker for Total Polyphenolic Content and Antioxidative Capacities of Peanut Cultivars," International Journal of Molecular Sciences, Vol. 10, 2009, pp. 4941-4952. doi:10.3390/ijms10114941

[27] Y. Shem-Tov, S. Galili, H. Badani, A. Segev, I. Hedvat and R. Hovav, "Determination of Total Polyphenol, Flavonoid and Anthocyanin Contents and Antioxidant Capacities of Skins from Peanut (Arachis hypogaea) Lines with Different Skin Colors," Journal of Food Biochemistry, Vol. 36, 2011, pp. 301-308. doi:10.1111/j.1745-4514.2011.00539.x

[28] M. Miranda, A. Vega-Gálveza, J. Lópeza, G. Paradac, M. Sandersa, M. Arandab, E. Uribea and K. D. Scala, "Impact of Air-Drying Temperature on Nutritional Properties, Total Phenolic Content and Antioxidant Capacity of Quinoa Seeds (Chenopodium quinoa Willd.)," Industrial Crops and Products, Vol. 32, No. 3, 2010, pp. 258-263. doi:10.1016/j.indcrop.2010.04.019

[29] R. Y. Nsimba, H. Kikuzaki and Y. Konishi, "Antioxidant Activity of Various Extracts and Fractions of Chenopodium quinoa and Amaranthus spp. Seeds," Food Chemistry, Vol. 106, No. 2, 2008, pp. 760-766. doi:10.1016/j.foodchem.2007.06.004

[30] Y. Hirose, T. Fujita, T. Ishii and N. Ueno, "Antioxidative Properties and Flavonoid Composition of Chenopodium quinoa Seeds Cultivated in Japan," Food Chemistry, Vol. 119, No. 4, 2010, pp. 1300-1306. doi:10.1016/j.foodchem.2009.09.008

[31] I. Arcan and A. Yemenicioglu, "Antioxidant Activity of Protein Extracts from Heat-Treated or Thermally Processed Chickpeas and White Beans," Food Chemistry, Vol. 103, No. 2, 2007, pp. 301-312. doi:10.1016/j.foodchem.2006.07.050

[32] H. Zielisnki and H. Koslowska, "Antioxidant Activity and Total Phenolics in Selected Cereal Grains and Their Different Morphological Fractions," Journal of Agricultural and Food Chemistry, Vol. 48, No. 6, 2000, pp. 2008-2016. doi:10.1021/jf990619o

[33] C.-T. Brady, R. Rosen, S. Sang and V. Karwe, "Effects of Processing on the Nutraceutical Profile of Quinoa," Food Chemistry, Vol. 100, No. 3, 2007, pp. 1209-1216. doi:10.1016/j.foodchem.2005.12.001

[34] M. Pasrija and D. Punia, "Effect of Pressure and Solar Cooking on Phytic Acid and Polyphenol Content of Cowpeas," Nutrition and Food Science, Vol. 30, No. 3, 2000, pp. 133-137. doi:10.1108/00346650010319732 
[35] M. Lindenmeier and T. Hofmann, "Influence of Baking Conditions and Precursor Supplementation on the Amounts of the Antioxidant Pronyl-L-Lysine in Bakery Products," Journal of Agricultural and Food Chemistry, Vol. 52, No. 2, 2004, pp. 350-354. doi:10.1021/jf0346657

[36] G. J. McDougall, P. Dobson and N. Jordan-Mahy, "Effect of Different Cooking Regimes on Rhubarb Polyphenols," Food Chemistry, Vol. 119, No. 2, 2010, p. 758. doi:10.1016/j.foodchem.2009.07.030

[37] K. B. Miller, D. A. Stuart, N. L. Smith, C. Y. Lee, N. L. Mchale, J. A. Flanagan, B. Ou and W. J. Hurst, "Antioxidant Activity and Polyphenol and Procyanidin Con- tents of Selected Commercially Available Cocoa-Containing and Chocolate Products in the United States," Journal of Agricultural and Food Chemistry, Vol. 54, 2006, pp. 4062-4068. doi:10.1021/jf060290o

[38] L. Stahl, K. B. Miller, J. Apgar, D. S. Sweigart, D. A. Stuart, N. McHale, B. Ou, M. Kondo and W. J. Hurst, "Preservation of Cocoa Antioxidant Activity, Total Polyphenols, Flavan-3-Ols, and Procyanidin Content in Foods Prepared with Cocoa Powder," Journal of Food Science, Vol. 74, No. 6, 2009, pp. C456-C461. doi:10.1111/j.1750-3841.2009.01226.x 